Agricultural Journal 14 (3): 30-34, 2019

ISSN: $1816-9155$

(C) Medwell Journals, 2019

\title{
Evaluation of Released Improved Coffee (Coffea arabica L.) Varieties for Growth and Yield Performance in the Mid Altitude of Assosa, Western Ethiopia
}

\author{
Nimona Fufa Hunde \\ Ethiopian Institute of Agricultural Research, Kulumsa Agricultural Research Center, \\ Horticulture Research Program, P.O. Box. 489 Asella, Ethiopia \\ nimona.43@gmail.com, +251925251032
}

\begin{abstract}
With an assumption of identifying adaptable coffee varieties that could exhibit higher yield to maximize coffee production and productivity to the environments of Assosa zone Western Ethiopia, the study was initiated at Assosa agricultural research center using seven released coffee varieties. The varieties which were used for the current study were transplanted in 2013 to the field in randomized block design to select and recommend better types which could exhibit relatively better performance at the area. The varieties were planted at a spacing of 2 by $2 \mathrm{~m}$ between plants and rows, respectively and they were grown with shade of Acesian spps and Sesbania sesban (temporary shade) were planted to provide regular shade over the plot. The data for plant height, number of primary branch per plant, stem diameter, leaf diameter and clean coffee yield was taken as parameters of the evaluation. From the evaluated varieties it was noted that the highest clean coffee yield $(1011.5,806.6,775.5 \mathrm{~kg} / \mathrm{ha})$ was scored by the $7440, \mathrm{~F} 59$ and 74110 varieties, respectively. On the contrary 74158 , 74140,7454 and 75227 exhibited least mean yields ranges from $603-701 \mathrm{~kg}$ of clean coffee per hectare. With the current results selections 7440 and F59 showed high results of clean coffee.
\end{abstract}

$\underline{\text { Key words: } \text { Arabica coffee, clean coffee, environments, released coffee varieties, yields, block design }}$

\section{INTRODUCTION}

Coffee belongs to the family Rubiaceae and genus Coffea L. comprised 104 species native to forests and scrublands of tropical Africa, Madagascar and the Mascarene Islands in the Indian Ocean (Davis et al., 2006) based on a pre-phylogenetic circumscription. A number of coffee-producing countries in Sub-Saharan Africa including Uganda, Ethiopia, Rwanda and Burundi, depend on the export of this commodity for more than half of their Foreign exchange earnings (Phiri et al., 2010). About $75 \%$ of the world's coffee comes from the tetraploid species Coffee arabica. It is native of the wet highland forests of Ethiopia where it grows wild.

In Ethiopia, coffee is produced organically as the bulk of the production comes from forest, semi-forest and home gardens where the use of inorganic fertilizers and chemicals is lacking. Economically, depending on prices on world market the share that comes from coffee still constitutes $25-40 \%$ of the national export (Efa et al., 2008). In addition about $25 \%$ of the population directly or indirectly depends on coffee industry through production, processing and marketing (Jirata and Assefa, 1999). The average yield in Ethiopia is low (about $700 \mathrm{~kg} / \mathrm{ha}$ per year) which is half of that achieved in Latin America and almost one third of Asia's productivity (Eshetu et al., 2000; Werkafes and Kassu, 1999). Such low yield is attributed to the lack of high yielding, disease resistant, lack of stable varieties that exhibit wide adaptation across wide ranges of environments of Arabica coffee in the country.

In Benishangul Gumuz Region, especially, Asosa zone is potentially conducive for cultivation and extension of the coffee crop. Information from BGRS showed that 5 and 7 qt production of clean coffee per hectare for garden and new plantation coffee production system, respectively. Different varieties have different response to a given environments, Jimma Agricultural Research Center released several coffee varieties for the country in general and also for particular area. It is critical to observe those varieties their adaptation and performance for Assosa areas. So, this study was initiated based on the following objective.

Objective: To evaluate the released coffee varieties for their adaptability and yield response to Assosa area and to maintain the selected varieties for future research.

\section{MATERIALS AND METHODS}

Description of the study area: The experiment will be conducted at Assosa Agricultural Research Center, during 2013- 2017 cropping season. The center is located at $10^{\circ} 02^{\prime} \mathrm{N}$ Latitude and $34^{\circ} 34^{\prime} \mathrm{E}$ Longitude in Western 
(a)
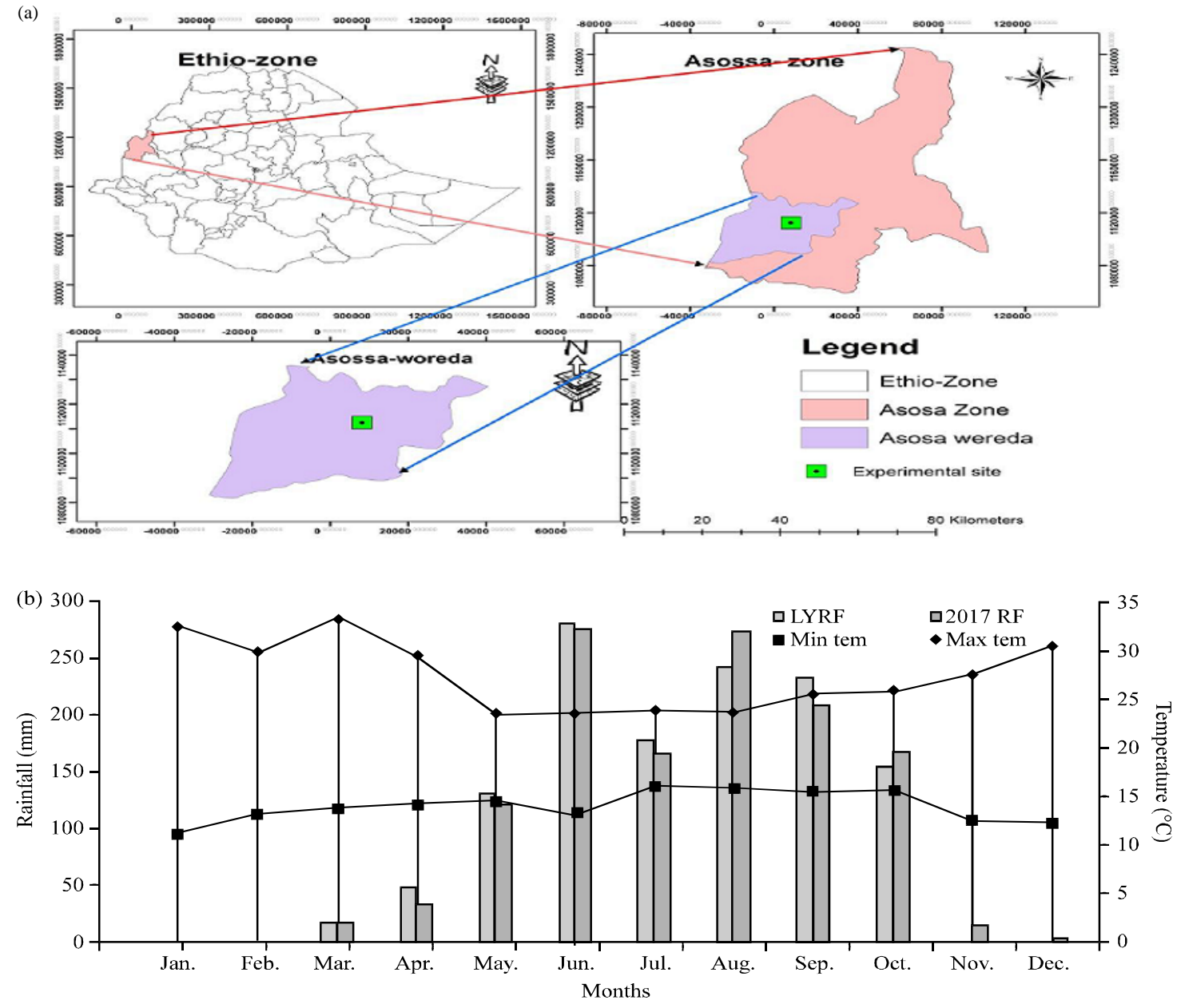

Fig. 1: a, b) Location map of the study area and the long term (2010-2017) rain fall of the area

Ethiopia. It is situated at $1553 \mathrm{~m}$ asl with mean annual rainfall of $1275 \mathrm{~mm}$. The rainy season extends from April to October and maximum rain is received in the months of June to August. It has a warm humid climate with mean maximum and minimum temperatures of 32.0 and $17.0^{\circ} \mathrm{C}$, respectively. The soil of the area is characteristically reddish, brown, nitosol which is slightly acidic, pH of 5.5 (EIAR., 2004) (Fig. 1).

Experimental procedure: The seven previously released CBD resistant varieties coffee which were collected from Jimma Agricultural Research Center where evaluated under Assosa location. The seedlings were raised at nursery which all nursery preparations and subsequent management practices were applied according to the established procedure or recommendation. Seeds (beans) were sown in polythene bags $(10 \times 10 \mathrm{~cm})$ filled with forest soil and managed for 10 months. Site selection and preparation were carried out prior to field transplanting. Other pertinent agronomic and horticultural practices applicable to coffee were also followed in the field based on the recommendation.

Treatments and experimental design: Treatments consisted of seven coffee varieties (75227, F59, 74140, $74158,7454,74110,7440$ ) were used. Accordingly, $40 \times 40 \mathrm{~cm}$ (depth $\mathrm{X}$ width) planting holes size were dug. Seedlings from the nursery bed were field planted in June 2013 using randomized complete block design with three replications, 12 trees per plot and $2 \times 2 \mathrm{~m}$ spacing between plants and raw. All field management practices were properly applied according to the recommendation. Sesbania sesban (temporary shade bush) and Acacia spps shade tree were planted before field transplanting of the coffee seedlings based on the recommended spacing to protect the coffee trees from direct sunlight. 
Data collection: Data were recorded for the following characteristics as plant height $(\mathrm{m})$, number of primary branch per plant, height up to primary branch $(\mathrm{cm})$, stem girth $(\mathrm{cm})$, canopy diameter $(\mathrm{cm})$, clean coffee yield (recorded in fresh cherry and converted to clean coffee bean yield per hectare).

Statistical data analysis: All the data were analyzed using Analysis of Variance (ANOVA) as proc GLM procedures of SAS Version 9.2 Statistical Software. The difference between treatment means was computed using the Duncan's Multiple Range Test (DMRT) at 5\% probability level. Pearson correlation was used to measure association of characters among themselves and clean coffee yield. Correlation analysis was made using proc corr procedures of SAS (Anonymous, 2002).

\section{RESULTS AND DISCUSSION}

The results of analysis of variance for all the parameters recorded were indicated in Table 1 discussed.

Plant height: Regarding plant height significant difference $(p \leq 0.05)$ was observed among the tested varieties throughout the growth period. The 7440 variety $(258.14 \mathrm{~cm})$ had significantly higher plant height than other varieties while 75227 variety had the lowest plant height $(201 \mathrm{~cm})$ and with over all mean of plant height ranged from $2.01-2.58 \mathrm{~m}$ per plant for all varieties Table 1 . The difference between the varieties could be attributed to the genetic variability among tested varieties this is because maximum phenotypic differentiation for a trait is expressed in optimum environments and genetic composition of varieties.

Height upto primary branches: The mean values of height upto primary branches were statistically non-significant differences $(\mathrm{p}<0.05)$ among the tested varieties. The varieties exhibited numerically the mean height up to primary branches ranges from $20.8-24.6 \mathrm{~cm}$ per plant.
Steam girth: The mean values showed that there were statistically significant differences $(p<0.05)$ in steam diameter among the tested varieties. The variety exhibited the mean steam diameter ranges from $2.93-4.27 \mathrm{~cm}$ per plant. However, variety 7440 and 74158 showed the highest $(4.27 \mathrm{~cm})$ and the lowest $(2.93 \mathrm{~cm})$ values for this characteristic, respectively.

Number of primary branch: The experimental varieties showed there were significant variations $(\mathrm{p}<0.05)$ in number of primary branch. The highest average number of primary branch (54.0) was recorded by 7440 variety, the average number of primary branch ranged from 40-54 Table 1 while variety 75227 had the least number of primary branch that 40.3 per plant.

Canopy diameter: The canopy diameter indicated that there was significant difference among the varieties of coffee. The highest canopy diameter ranges from $208.5 \mathrm{~cm}$ was scored by 7440 variety. While the rest of testing material scored $131-200 \mathrm{~cm}$ average mean value of canopy diameter per plant.

Clean coffee yield: Significant differences $(\mathrm{p}<0.05)$ among the varieties were observed for clean coffee yield per hectare. The highest mean clean yield was recorded for 7440 followed by F59 with values 1011.5 and $806.6 \mathrm{~kg} / \mathrm{ha}$, respectively. The lowest mean clean yield on the other hand was obtained from 7454 with value of $603 \mathrm{~kg} / \mathrm{ha}$. However, this value was statistically not different from values recorded for most of the released varieties except the 7440 top yielders Table 1 .

In general, all the evaluated varieties revealed variable performance with regard to clean coffee yields per hectare. Only one variety, namely, 7440 have showed highest yield variation with average performance of about $10 \mathrm{qt} / \mathrm{ha}$ while statically significant variation from other varieties, the remaining six varieties did not statically exhibit better performance but from those F59 were the second performed variety. Thus, this indicated that 7440 have better adaptive potential to the environment

Table 1: Improved CBD resistance Arabica coffee varieties evaluated for growth and yield components at Assosa

\begin{tabular}{|c|c|c|c|c|c|c|}
\hline Varieties & $\mathrm{pH}(\mathrm{cm})$ & $\mathrm{HPB}(\mathrm{cm})$ & $\mathrm{SG}(\mathrm{cm})$ & NPB & $\mathrm{CD}(\mathrm{cm})$ & CY kg/ha \\
\hline 75227 & $200.53^{\mathrm{d}}$ & 23.2 & $3.1^{b c}$ & $40.33^{b}$ & $200.5^{\mathrm{ab}}$ & $701.49^{\mathrm{bc}}$ \\
\hline F59 & $233.73^{b}$ & 22.8 & $3.73^{\mathrm{ab}}$ & $50.0^{\mathrm{ab}}$ & $183.67^{\mathrm{abc}}$ & $806.63^{b}$ \\
\hline 74140 & $212.24^{\mathrm{cd}}$ & 21.3 & $3.13^{b c}$ & $43.67^{\mathrm{ab}}$ & $170.83^{\mathrm{abc}}$ & $653.21^{b c}$ \\
\hline 74158 & $201.0 \mathrm{~d}$ & 20.8 & $2.93^{\mathrm{c}}$ & $44.67^{\mathrm{ab}}$ & $148 \mathrm{~cd}$ & $643.54^{b c}$ \\
\hline 7454 & $200.73^{d}$ & 21.1 & $3.17^{\mathrm{bc}}$ & $44.33^{a b}$ & $168.83^{b c d}$ & $603.33^{c}$ \\
\hline 74110 & $224.33^{\text {bc }}$ & 24.6 & $3.57^{\mathrm{abc}}$ & $48.33^{\mathrm{ab}}$ & $131.17^{\mathrm{d}}$ & $775.59^{\mathrm{bc}}$ \\
\hline 7440 & $258.67^{\mathrm{a}}$ & 21.6 & $4.27^{\mathrm{a}}$ & $54.0^{\mathrm{a}}$ & $208.5^{a}$ & $1011.45^{\mathrm{a}}$ \\
\hline $\mathrm{CV}$ & 3.56 & 11.68 & 12.65 & 15.23 & 12.73 & 14.44 \\
\hline LSD & 13.873 & NS & 0.7686 & 12.595 & 39.223 & 190.64 \\
\hline
\end{tabular}

$\mathrm{CV}=$ Coefficient of Variation, LSD = Least Significant Difference, Ns = None significant difference, Values with the same letter (s) are not significantly difference, $\mathrm{PH}=$ Plant Height $(\mathrm{cm}), \mathrm{HPB}=$ Height up to Primary Branch, $\mathrm{SG}=$ Steam Girth $(\mathrm{cm}), \mathrm{NPB}=$ Number of Primary Branch, CD $=$ Canopy Diameter $(\mathrm{cm}), \mathrm{CY}=$ Clean coffee Yield $(\mathrm{kg}),{ }^{\mathrm{a}-\mathrm{d}}$ : Significant values 
Agric. J., 14 (3): 30-34, 2019

Table 2: Pearson's correlation (r) of clean coffee yield and its components of coffee varieties

\begin{tabular}{|c|c|c|c|c|c|c|}
\hline Variables & $\mathrm{CY}$ & $\mathrm{pH}$ & $\mathrm{HPB}$ & $\mathrm{SG}$ & $\mathrm{CD}$ & $\mathrm{PB}$ \\
\hline CY & 1 & & & & & \\
\hline $\mathrm{PH}$ & $0.50925^{* *}$ & 1 & & & & \\
\hline HPB & $0.29981^{*}$ & $0.21566^{*}$ & 1 & & & \\
\hline $\mathrm{SG}$ & $0.42102^{* *}$ & $0.71251^{* *}$ & $0.44722^{*}$ & 1 & & \\
\hline $\mathrm{CD}$ & $0.3492^{* *}$ & $0.33217^{* *}$ & $0.31014^{* *}$ & $0.07425^{*}$ & 1 & \\
\hline$\underline{\mathrm{PB}}$ & $0.59519^{* *}$ & $0.55803^{* *}$ & $-0.0719^{n s}$ & $0.43679^{* *}$ & $0.27887^{*}$ & 1 \\
\hline
\end{tabular}

*,*: Significant correlation at $\mathrm{p}<0.05$ probability levels, ns: non significant, $\mathrm{CY}=$ clean Coffee Yield, $\mathrm{PH}=$ Plant Height, HPB $=$ Height up to Primary Branch, $\mathrm{SG}=$ Stem Girth, $\mathrm{PB}=$ Primary Branches

where this experiment is executed than the remaining ones. The yield difference could be attributed to the fact that genotypes usually exhibit different responses to the environment. These are potential variables which induces genotype by environment interaction and only genotypes with wide adaptation across such environments butter yield stability this is in line with research by Hammer.

Correlation coefficient analysis: Correlation analysis showed that plant height $\left(\mathrm{r}=0.51^{* *}\right)$, number of primary branches $\left(\mathrm{r}=0.59^{* *}\right)$, canopy diameter $\left(\mathrm{R}=0.35^{*}\right)$ and stem girth $\left(\mathrm{r}=0.42^{* *}\right)$ were highly significantly and positively correlated with clean coffee yield per hectare Table 2 this indicating that those characters have strong tie to improve productivity of coffee per tree basis. Pearson correlation ( $r$ ) of plant height was highly significantly and positively correlated with stem diameter $(\mathrm{r}=0.71)$, number of primary branch $(\mathrm{r}=0.56)$ and canopy diameter $(\mathrm{r}=0.33)$ while height up to primary branches $(r=-0.07)$ was non significantly and negatively correlated. All the above positive and strong association of growth characters implies those components are most important for clean coffee yield improvement at Assosa area.

\section{CONCLUSION}

The released varieties showed differential response to the tested environment. The result of almost all of the parameters as plant height number of primary branch per plant, steam girth, canopy diameter and clean coffee yield recorded was statically significant difference among varieties, except height up to primary branch which is non significant difference. From the present evaluation it was noted that the highest clean coffee yield (1011.5 and $806.3 \mathrm{~kg} / \mathrm{ha}$ ) was scored by coffee genotypes $7440 \mathrm{~F} 59$ variety, respectively. On the contrary $7454,75227,74158$, 74140 and 74110 exhibited least mean yields ranges from $603-775 \mathrm{~kg}$ of clean coffee per hectare. The relationship of the growth characters were significantly and strongly correlated $(\mathrm{p}<0.05)$ with clean coffee yield, this indicates the improvement of clean coffee yield was through most of growth parameters.

\section{RECOMMENDATIONS}

From this study, it was concluded that variety 7440 and F59 produce better plant height number of primary branches, canopy diameter and clean coffee yield to the environment indicates a good performance and adaptation. Therefore, this variety was suggested to be produced by farmers at the study area.

\section{REFERENCES}

Anonymous, 2002. Users guide: Version 9.2.NC.USA. SAS Institute, Cary, North Carolina, USA.

Davis, A.P., R. Govaerts, D.M. Bridson and P. Stoffelen, 2006. An annotated taxonomic conspectus of the genus Coffea (Rubiaceae). Bot. J. Linnean Soc., 152: 465-512.

EIAR., 2004. Ethiopian institute of agricultural research directory of released crop varieties and their recommended cultural practices. Ethiopian Institute of Agricultural Research, Addis Ababa, Ethiopia.

Efa, N., D. Teshome, B. Megersa and G. Woldemichael, 2008. Research center-based extension interventions on improved coffee technologies. Proceedings of the National Workshop on four Decades of Coffee Research and Development in Ethiopia, August 14-17, 2008, Ethiopian Institute of Agricultural Research, Addis Ababa, Ethiopia, pp: 345-356.

Eshetu, D., G. Teame and A. Girma, 2000. Significance of minor diseases of Coffea arabica L. in Ethiopia: A review. Proceedings of the Workshop on Control of Coffee Berry Disease (CBD) in Ethiopia, August 13-15, 1999, Agricultural Research Organization, Addis Ababa, Ethiopia, pp: 58-65.

Jirata, M. and S. Assefa, 1999. The status of coffee berry disease in Oromia. Proceedings of the International Workshop on Control of Coffee Berry Disease in Ethiopia, August 13-15, 1999, Ghion Hotel, Addis Ababa, Ethiopia, pp: 9-17. 
Phiri, N., P. Baker, M. Rutherford, J. Flood and P. Musoli et al., 2010. The regional coffee wilt program: Where do we go. Proceedings of the 23rd International Scientific Colloquium on Coffee Science, October 3-8, 2010, Bali, Indonesia, pp: 537-548.
Werkafes, W. and K. Kassu, 1999. Coffee production systems in Ethiopia. Proceedings of the International Workshop on Control of Coffee Berry Disease (CBD) in Ethiopia, August 13-15, 1999, Ethiopian Agricultural Research Institute, Addis Ababa, Ethiopia, pp: 99-106. 